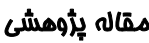

\section{درمان كراتكتازى يس ازليزيك با استفاده از كراس لينكينگ قرنيه با ريبوفلاوين و UV-A}

حميد خاكشور'، لادن صفاريان'، على خاكشور '، اميرحسين وجدانى "، مسعود شفيعى"، سعيد شكوهى راده

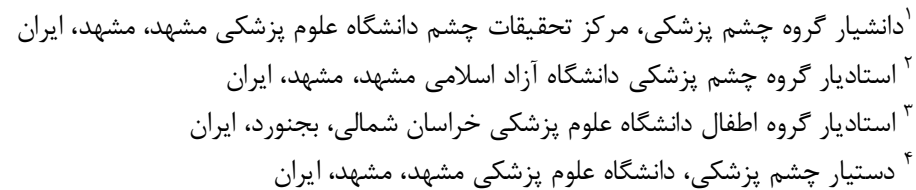

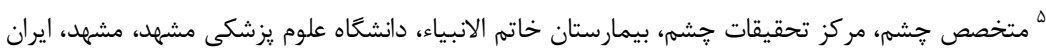

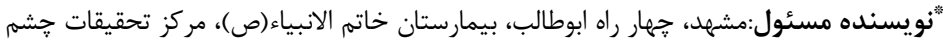
يست الكترونيك: amirhosein_vejdani@yahoo.com

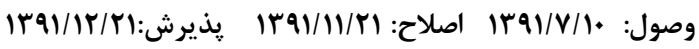

جكيده

زمينه و هدف: كراتكتازى يك عارضه تهليد كننده بينايى مى باشد كه ممكن بـ از عمل ليزيك / يجاد شود. مطالعه حاضر با هدف

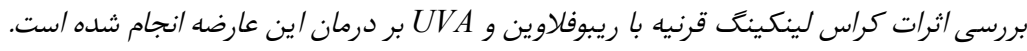

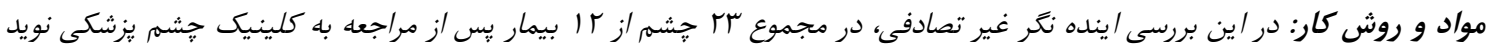

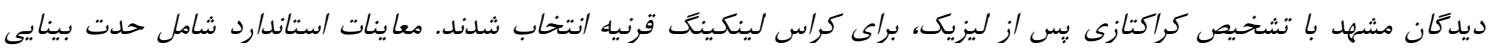

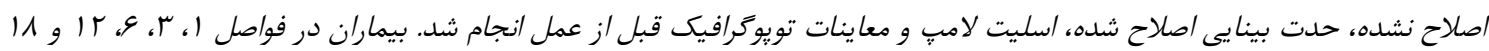

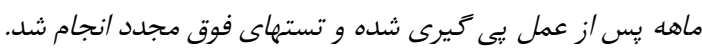

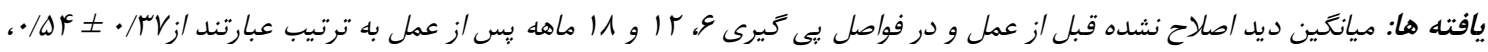

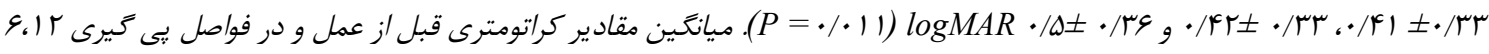
و 11 ماهد يس از عمل به ترتيب عبارتند /

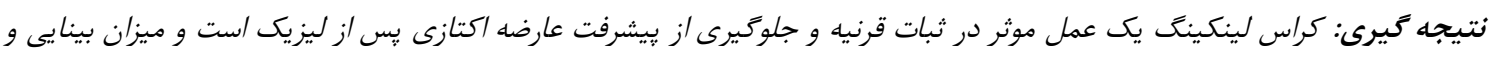
كراتومترى را بهبود مى بخشد.

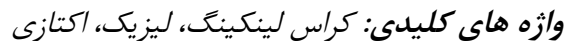

كراس لينكينگ با ريبوفلاوين و اشعه UV مى تواند ساختمان استروماى قرنيه را تغيير دهد. اين : يروسه منجر به تشكيل باندهاى كووالانت اضافى بين فيبرهاى كلازن و در نتيجه افزايش قدرت و گايدارى قرنيه در اثر افزايش

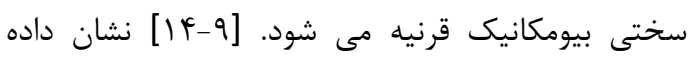
شده است كه كراس لينكينگ قرنيه در يايدارى حدت برت

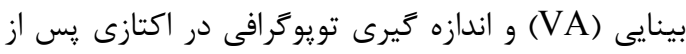

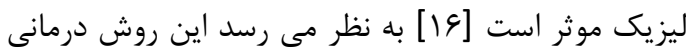
يكى روش كم خطر براى توقف بيشرفت سير اكتازى به

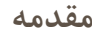
كراتكتازى به عنوان يك عارضه تهديد كننده بينايى ريس از ليزيك محتمل است. ميزان واقعى بروز آن ناشناخته است و از نظر زمانى ممكن است بلافاصله يس از ليزيك

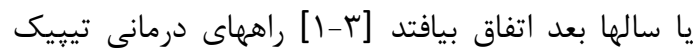
براى كنترل اكتازى يس از ليزيك شامل موارد زير است: استفاده از لنز تماسى سخت، داروهاى كاهنده فشار داخل

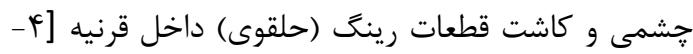
1] در بعضى موارد ممكن است نياز به ييوند قرنيه باشد. 
استفاده از يك دستگاه سنجش UVA كاليبره

(LaserMate-Q, LASER2000, Wessling, F قرار گرفت. در طى تابش، ريبوفلاوين هر Germany) دقيقه استفاده شد و از يك محلول نمكى متعادل براى

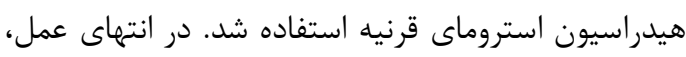
(CIBA Vision, Duluth, GA, يك لنز تماسى بانداز بSA) استروئيد، آنتى بيوتيكى و قطره اشك مصنوعى براى تمام بيماران استفاده شد. پس از إيى تليزاسيون مجدد (حدود بيون

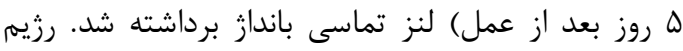

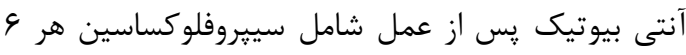

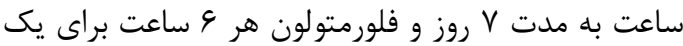
ماه و سيس با كم كردن آن به يك قطره در هفته ادامه

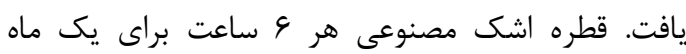
ستفاده شد. كليه معاينات استاندارد قبل از مطالعه (بجز دانسيته

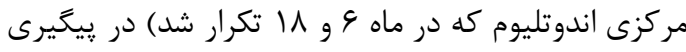

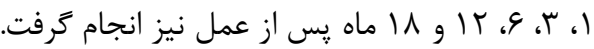
تمام بررسى هاى آمارى توسط نرم افزار SPSS ويرايش

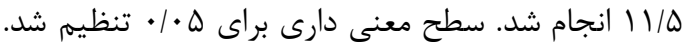

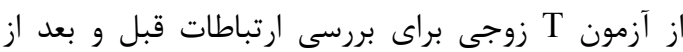
عمل استفاده شد.

يافته ها

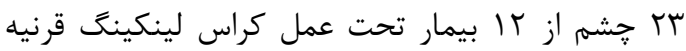

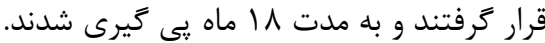

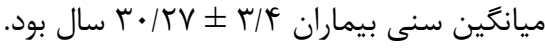

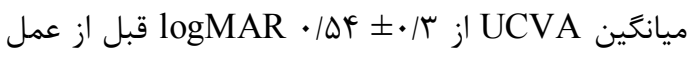

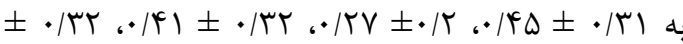

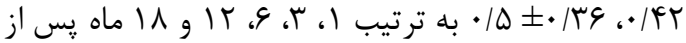

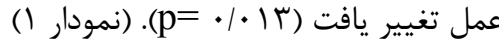
ميانغين BCVA از BCV عمل به 9 •|• 快

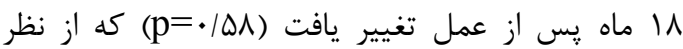

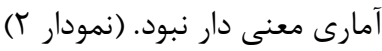

معادل اسفريكال (SE) تغييرات غير معنى دارى را نشان

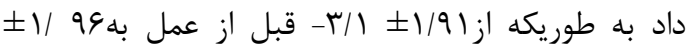

سمت از دست دادن بينايى مى شود [ه|،19] حتى در بعضى مطالعات رگرشن نشان داده شده است [19]. در اين مطالعه ما به بررسى ايمنى و كارايى كراس

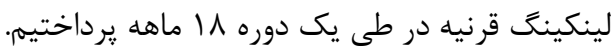

روش كار

در يك مطالعه آينده نخر غيرتصادفى، سץ جشم از بيمار كه در مدت لها سال كذشته ليزيك شده و و با

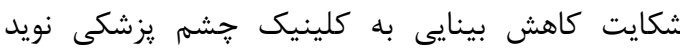
ديدكان مراجعه نمودند (V زن و ه مرد) يس از اخذ فرم رضايت اخاهانه وارد مطالعه شدند. تشخيص كراتكتازى بر

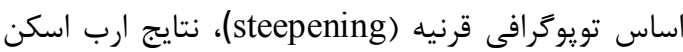
و (Bausch and Lomb, Rochester, NY, USA) II علائم بالينى اكتازى (افزايش DD 1 DD يا بيشتر، كاهش ضخامت قرنيه، كاهش بينايى يا رفركشن غير يايدار) است.

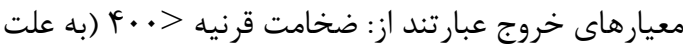

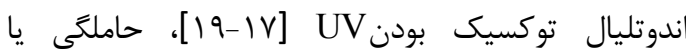
شيردهى و تاريخجه ترميم إيى تليال تاخير افتاده. آزمايشات قبل از عمل شامل اندازه گيرى بينايى اصلاح نشده (UCVA)، بهترين ديد اصلاح شده ( BCVA ) توسط جارت حدت بينايى درمان زودرس ديابتيك رتينوياتى (ETDRS ) و لعاريتم زاويه ( logMAR )، اندازه گيرى فشار داخل جشمى ( توسط دستغاه Gold man اندوتليال. رفركن مانيفست و و راكى مترى Nidek and) Orbscan II) تحت شرايط استريل در اتاق عمل براى تمام بيماران يك نئ لـدام نوع عمل مشابه انجام شد. يس از بى حسى موضعى اتانول

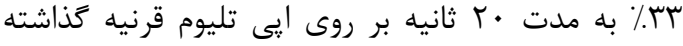
شد. إيى تليوم مركزى به آرامى دبريد شد (1 ميلى متر).

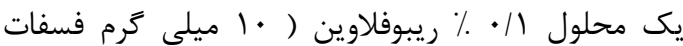

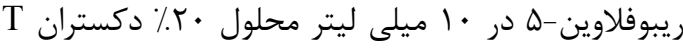

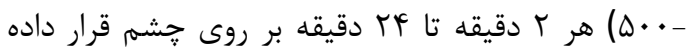
شد. يس از اثبات حضور ريبوفلاوين در بافت قرنيه و اتاق قدامى، قرنيه تحت يرتوافكنى با دستخاه كاليبره شده (IROC, Zurich, Switzerland) UV-X دقيقه و با تابش سطحى mw/m2 (دوز سطحى m2

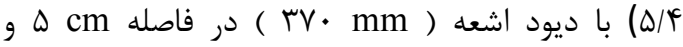




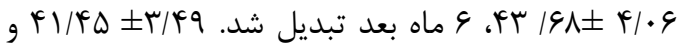

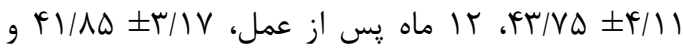

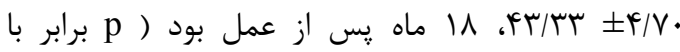

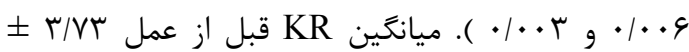

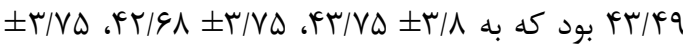

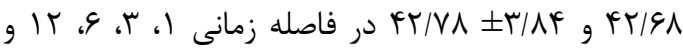

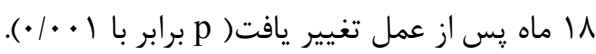

اختلاف امارى بين شمارش سلولهاى اندوتليال مركزى

قبل از كراس لينكينگ

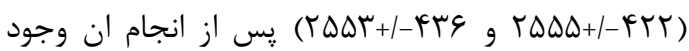

نداشت (p) $r V$ ، $-r / 9 \pm r / 1 \Lambda$ ، $r / \Lambda Y \pm r / \cdot 9$ ، $r / 11 \pm 1 / 9 \Lambda$ ، $-r / r q$

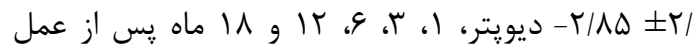
تغيير كرد. (p=/rV) (نمودار r) سيلندر مانيفست ازئ

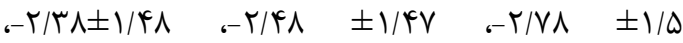
ع

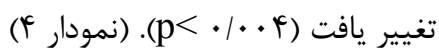
اندازه گيرى هاى تويوگرافيك در جدول ا نشان داده شده

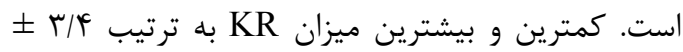

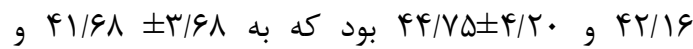
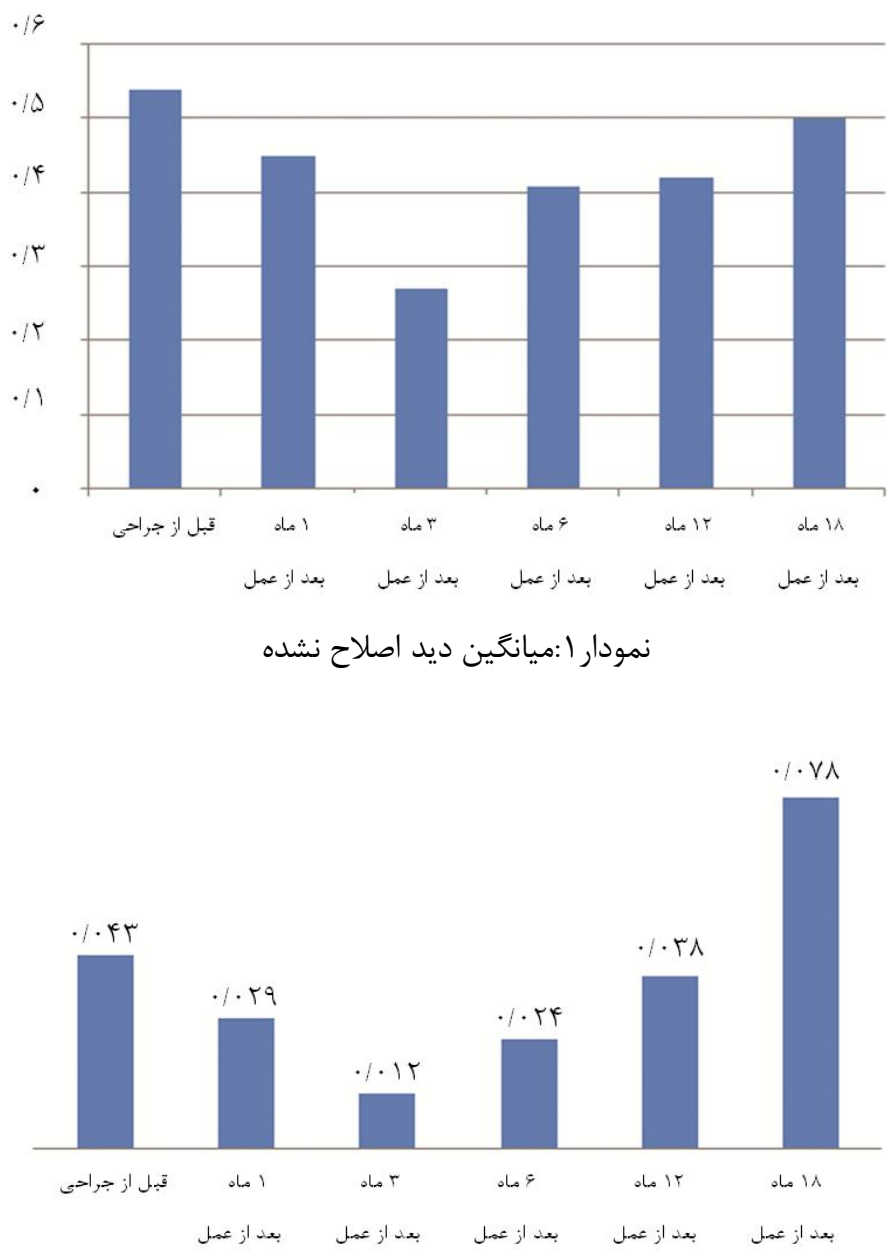

نمودار Y:ميانگين بهترين ديد اصلاح شده 


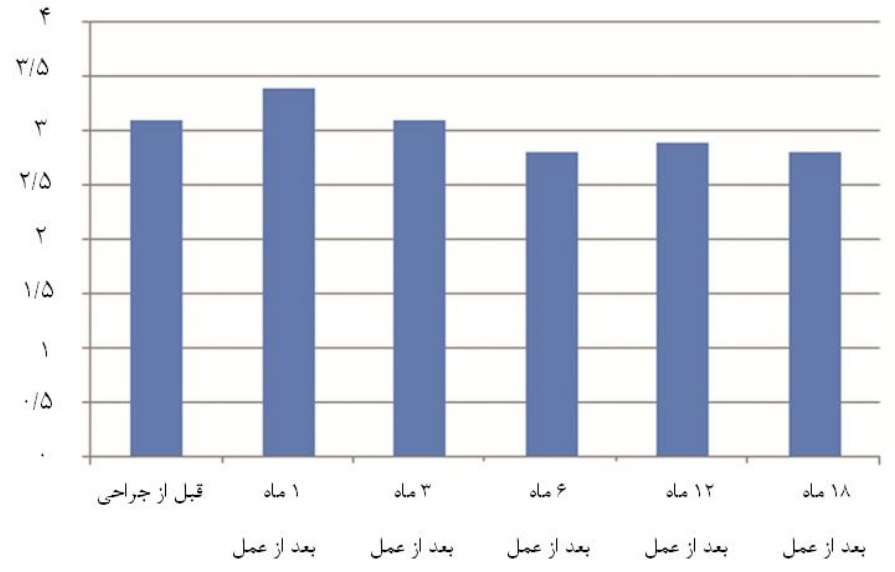

نمودار با: تغييرات معادل كروى (SE)

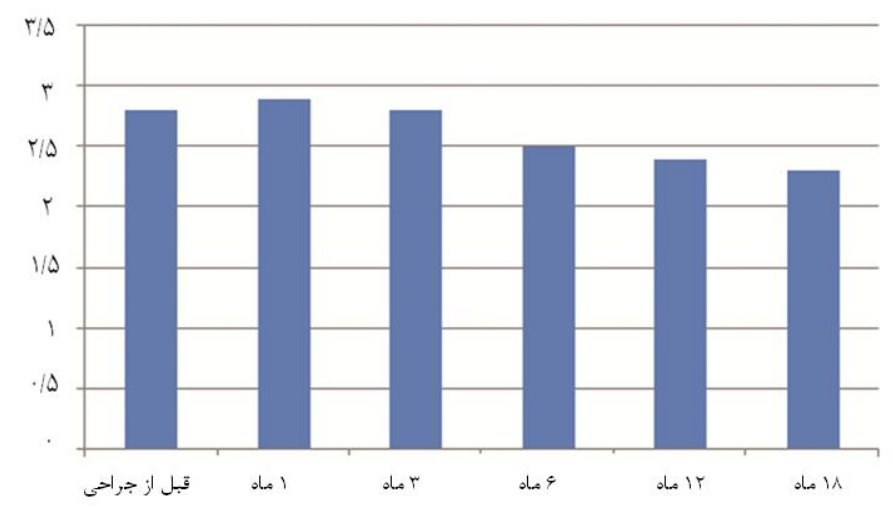

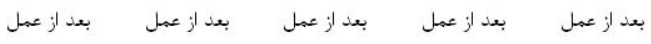

manifest نمودار †:تغييرات آستيگماتيسم

جدول ا اندازه كيرى هاى تويوكرافيك

K-readings

\begin{tabular}{|c|c|c|c|c|c|c|}
\hline 1) ماه پِ از & זا ماه پِ از & عماه يس از عمل & 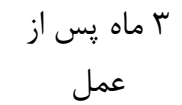 & يك ماه يس از & قبل از عمل & يارامتر \\
\hline$\langle/ / \Lambda \Delta \pm r / / V$ & $\mid q / / \uparrow \Delta \pm r / \uparrow q$ & $\forall / / 9 \Lambda \pm r / 9 \Lambda$ & $f l / q \pm r / f q$ & $F r / F \pm r / F r$ & $F r / 1 G \pm \Gamma / F$. & كمترين \\
\hline Fr/Tr $\pm F / V$ & $\kappa r / v \Delta \pm \psi / 11$ & $\psi r / q \Lambda \pm \psi /$. & 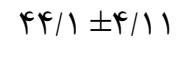 & $r \Delta / \cdot \pm r / r q$ & $\kappa \psi / V \Delta \pm \psi / r$. & ميانگين \\
\hline$F Y / V \Lambda \pm r / \Lambda F$ & $F r / G \Lambda \pm r / V \Delta$ & $F r / G \Lambda \pm r / V \Delta$ & $\psi \Psi / \cdot V \pm r / \varphi D$ & $\kappa r / V \Delta \pm r / \Lambda$ & $r r / F q \pm r / v r$ & بيشترين \\
\hline
\end{tabular}


طبق نظر سالكَادو' و همكارانش مهمتر ين قدم در مديريت

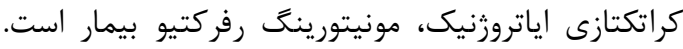
مشابه گزارش هاى ديكر بيماران ما كدورت خفيف و كذرا

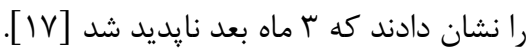
براى اينكه عارضه تهديد كننده بينايى كراكتازى به حداقل برسد بايستى از انجام جراحى عيوب انكسارى در

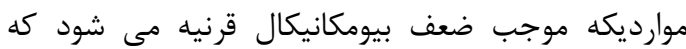
عمدتا افراد مشكوك به كراتوكونوس مى باشند ويا

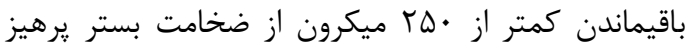

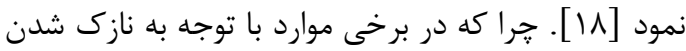

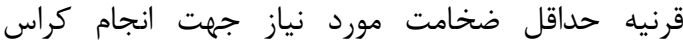

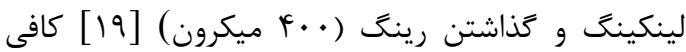

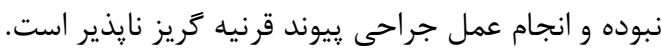
در انتها با توجه به محدوديت تعداد بيماران مطالعات

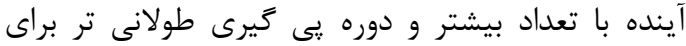

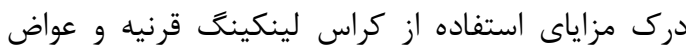
احتمالى اين عمل بعد از ليزيك پِيشنهاد مى شود.

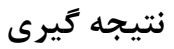
كراس لينكينگ يك عمل موثر در ثبات قرنيه و جلوكيرى

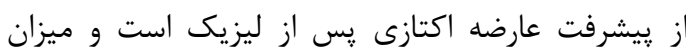

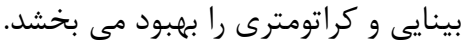

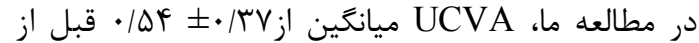
كراس لينكينَ قرنيه به وب /• عمل تغيير يافت. هيج كدام از بيماران 1 خط از جارت

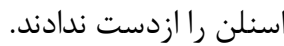

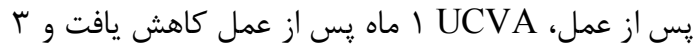

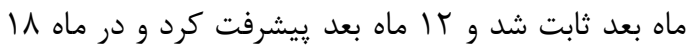

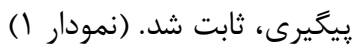
روند مشابهى در VA در مطالعات ديكر كزارش شده است. تغييرات VA با تغييرات معادل رفركتيو اسفريكال همراه شد. ماه اول تغييرات ميويى در بيماران (MRSE)

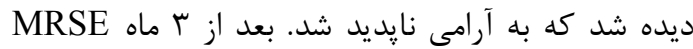
شروع به كاهش و VA شروع به افزايش كرد. تقريبا تمام بيماران تارى ديد يا كاهش بينايى را در ماه اول تجربه

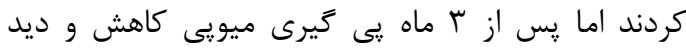

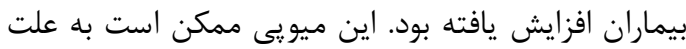
روند بازسازى قرنيه در طى كراس لينكينگ باشد كه دئ درد

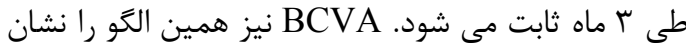

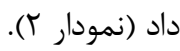

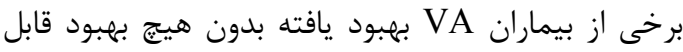
توجهى در عيوب انكسارى (كاهش نزديك بينى) را نشان

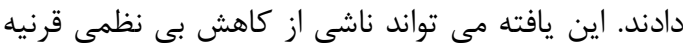

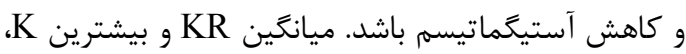
كاهش استيب شدن قرنيه و در برخى موارد فلت شدن ناحيه اكتازى را نشان داد.

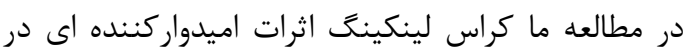

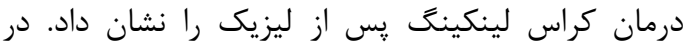

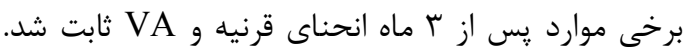

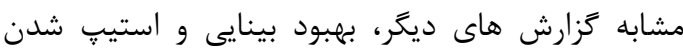

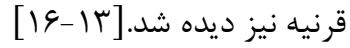
جون زمان دقيق شروع اكتازى مشخص نيست و اساس

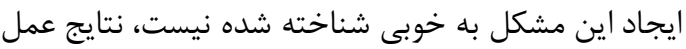

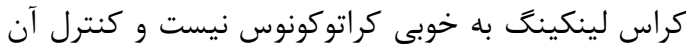

به نظر مشكل است [10].

1-Salgado 


\section{References}

1. Krachmer JH, Feder RS, Belin MW. Keratoconus and related noninflammatory corneal thinning disorders ,Surv Ophthalmol 1984; 28(4):293-322.

2. Comash IF, Lowless MA, progressive post-

Page | 568

lasikkeratectasia: biomechanical instability orchronic disease process? J cataract refract surg 2002; 28(12):2206-13.

3. Seiler T, Koufala K, Richter G, Iatrogenic keratectasia after laser in situ keratomileusis, $\mathrm{J}$ cataract refract surg 1998 May-June; 14(3): 312-17.

4. Lembach RG, Use of contact lenses for management of keratoconus, Ophthalmol Clin N Am 2003 Sept; 16(3):383-94.

5. Coskunseven E, Kymionis GD, Tsiklis NS, "et al",One year results of intrastomal corneal ring segment implantation (Kera Ring) using femtosecond laser in patients withkeratoconus ,Am J Ophthalmol 2008 May; 145(5):775-9.

6. Shetty R, Kurian M, Anand D, Mhaske P, Narayana KM, Shetty BK, Intacs in advanced keratoconus, Cornea 2008; 27(9):1022-29.

7. Rabinowitz YS, Intacs for keratoconus, Curv Opin Ophthalmol 2007; 18(4):279-83.

8. Tan DT, Por YM ,Current treatment option for corneal ectasia, Curv Opin Ophthalmol 2007; 18(4):284-9.

9. Bilgihan K, Ozdek SC, Sari A, Hasanreisoğlu B, Excimer laser assisted anterior lamellar keratoplasty for keratoconus corneal problems after laser in situ keratomileusis and corneal stromal opacities, J cataract Refract Surg 2006; 32(8):1264-9.

10. Rodriguez LA, Guillen PB, Benavides MA, Garcia L, Porras D, Daqui-Garay RM. penetrating keratoplasty versus intrastromal corneal ring segments to correct bilateral corneal ectasia : preliminary study, J Cataract Refract Surg. 2007; 33 (3):488-96.

11.Hafezi F, Kanellopoulos J, Wiltfag R, Seiler $\mathrm{T}$, Corneal collagen crosslinking with riboflavin and ultraviolet $\mathrm{A}$ to treat induced keratectasia after laser in situ keratomileusis, J Cataract RefractSurg 2007; 33(12); 2035-40.

12.Saffarian L, Khakshoor H, ZareiGhanavati $\mathrm{M}$, Corneal crosslinking for keratoconus in Iranian patients, MEAJO 2010; 17(4); 36569[Persian].

13. Wollensak G, crosslinking of progressive keratoconus: new hope, Curv Opin Ophthalmol 2006; 17 (4):356-60.

14. Kohlhaas M, Collagen crosslinking with riboflavin and UVA-light in keratoconus, Ophthalmoge 2008; 105(8):785-93.

15. Salgado JP, Khoramnia R, Lohmann CP, "et al", Corneal collagen crosslinking in postLASIK keratectasia,Br J Ophthalmol 2011;95(4):493-7.

16.Hersh PS, Greenstein S A, Fry KL, Corneal collagen crosslinking for keratoconus and corneal ectasia, J Cataract Refract Surg 2011; 37(1):149-160.

17.Koller T, Mrochen M, Seiler T, Complication and failure rates after corneal crosslinking, J Cataract Refract Surg. 2009; 35(8):1358-62.

18. Dimitri T,Azar, Refractive surgery, second edition,LASIK complication and their management,2007;212:14.

19. Goldich Y,Marcovich AL,BarkanaY,"et al",Safety of corneal collagen cross-linking with UV-A and riboflavin in progressive keratoconus,Cornea.2010;29(4):409-11. 
Original Article

\title{
Effect of Corneal Crosslinking With Riboflavin UV-A forTreatment of Post-Laser in Situ Keratomileusis Keratectasia
}

\author{
Khakshoor $H^{l}$, Saffarian $L^{2}$, Khakshoor $A^{3}$, Vejdani $A H^{4} *$, Shafiee $M^{4}$, Shokoohi Rad $S^{5}$ \\ ${ }^{1}$ Associate Professor of Ophthalmology(cornea fellowship),Eye Research Center, Khatam-al-Anbia Hospital, \\ Mashhad University of Medical Sciences, Mashhad, Iran. \\ ${ }^{2}$ Assistant Professor of Ophthalmology, Islamic Azad University of Medical Sciences, Mashhad, Iran. \\ ${ }^{3}$ Assistant Professor of Pediatric,North Khorasan University of Medical Sciences,Bojnurd, Iran. \\ ${ }^{4}$ Resident of ophthalmology, Eye Research Center, Khatam-al-Anbia Hospital, Mashhad University of \\ Medical Sciences . \\ ${ }^{5}$ Ophthalmologist (cornea fellowship), Eye Research Center, Khatam-al-Anbia Hospital, Mashhad University \\ of Medical Sciences
}

$\begin{array}{lr}\text { *Corresponding } & \text { Author: } \\ \text { Khatam-al-Anbia } & \text { Hospital, } \\ \text { Eye Research } & \text { Center, } \\ \text { Mashhad,Iran } & \\ \text { Email: } \\ \text { amirhosein_vejdani@yahoo.co } \\ \text { m }\end{array}$

\begin{abstract}
Background \& Objectives: keratectasia is a sight-threatening complication that may occur after LASIK. The purpose of this study was to evaluate the effects corneal crosslinking with riboflavin and UVA for treatment of this complication.

Material \& Methods: Twenty-three eyes of 12 patients in Non-Randomize Cohort study (referred to Navididegan Clinic) were selected for corneal crosslinking. Standard examinations like: UCVA-BCVA-slit lamp examination, topography were performed preoperatively and 1, 3, 6, 12 and 18 months after the procedure.

Results: The mean UCVA was $0.54 \pm 0.37$ LogMAR preoperatively that changed to $0.41 \pm 0.33,0.42 \pm 0.33$ and $0.5 \pm 0.36$ LogMAR in 6,12 and18 months postoperation respectively $(p=0.011)$. Mean simk was $43.49 \pm 3.72$ preoperatively and changed to $42.68 \pm 3.75,42.62 \pm 3.8$ and $42.78 \pm 3.84$ in 6,12 and 18 months postoperative respectively.

Conclusion: Crosslinking seems to be a safe procedure for stabilizing the progression of ectasia with stabilizing and improvement of UCVA and k-readings.

Key words: Crosslinking' ectasia 'lasik
\end{abstract}

Submitted:1 Oct 2012

Revised:9 Feb 2013

Accepted: 11Mar 2013 